\title{
Interactive effects of dietary fibre and lipid types modulate gastrointestinal flows and apparent digestibility of fatty acids in growing pigs
}

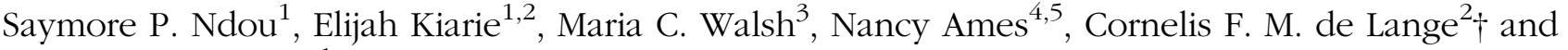 \\ Charles M. Nyachoti ${ }^{1 *}$ \\ ${ }^{1}$ Department of Animal Science, University of Manitoba, Winnipeg, MB, Canada R3T 2N2 \\ ${ }^{2}$ Department of Animal Biosciences, University of Guelph, Guelph, ON, Canada N1G 2W1 \\ ${ }^{3}$ Danisco Animal Nutrition-DuPont Industrial Biosciences, Marlborough, Wiltshire SN8 1XN, UK \\ ${ }^{4}$ Agriculture and Agri-Food Canada, Richardson Centre for Functional Foods and Nutraceuticals, Winnipeg, MB, \\ Canada R3T 6C5 \\ ${ }^{5}$ Department of Human Nutritional Sciences, University of Manitoba, W383 Duff Roblin Building, Winnipeg, MB, \\ Canada R3T 2N2 \\ (Submitted 11 June 2018 - Final revision received 5 November 2018 - Accepted 6 November 2018 - First published online 11 December 2018)
}

\section{Abstract}

A total of eight ileal and caecal cannulated Yorkshire barrows were used to determine the interactions of dietary fibre (DF) and lipid types on apparent digestibility of DM and fatty acids (FA) and FA flows in gastrointestinal segments. Pigs were offered four diets that contained either pectin or cellulose with or without beef tallow or maize oil in two Youden square designs $(n 6)$. Each period lasted $15 \mathrm{~d}$. Faeces, ileal and caecal contents were collected to determine apparent ileal digestibility (AID), apparent caecal digestibility and apparent total tract digestibility (ATTD) of dietary components. The interactions between DF and lipid types influenced $(P<0.05)$ the digestibility of DM and FA flows. The addition of maize oil decreased $(P<0.05)$ AID of DM in pectin diets, and the addition of beef tallow depressed $(P<0.001)$ ATTD of DM in cellulose diets. Dietary supplementation with beef tallow decreased $(P<0.05)$ the AID of FA in pectin-containing diets but had no effects in cellulose-containing diets. Dietary supplementation with beef tallow increased $(P<0.05)$ AID of SFA and PUFA and the flow of ileal oleic, vaccenic, linolenic and eicosadienoic acids and reduced the flow of faecal lauric, docosatetraenoic and docosapentaenoic acids in pectin- and cellulose-containing diets. In conclusion, the interaction between DF type and lipid saturation modulates digestibility of DM and lipids and FA flows but differs for soluble and insoluble fibre sources, SFA and unsaturated fatty acids and varies in different gastrointestinal segments.

Key words: Digestibility of fat: Fatty acid flows: Hindgut fermentation: Pigs: Soluble dietary fibre

Low-cost agro-industrial co-products are increasingly being used in pig diets, resulting in increased dietary fibre (DF) content. High-fibre diets are supplemented with lipids to meet the energy requirement for a nutritionally balanced diet for pigs. A common assumption is that growth performance in pigs fed nutritionally balanced high-fibre diets that are supplemented with added lipids will not decline. However, pigs fed fibrous diets based on cereal co-products plus supplementary fat reportedly had lower growth performance and nutrient utilisation, compared with those offered high-fibre diets that are composed of cereals or cereal co-products without added fats ${ }^{(1-5)}$. This paradoxical relationship suggests that the understanding of the interaction between DF solubility and the degree of saturation of fatty acids (FA) in dietary lipids in pigs is far from complete.
The interactions between dietary fibre and lipid types may be hydrogen bonding or electrostatic as well as hydrophobic interactions $^{(6)}$. During these interactions, DF polysaccharides may non-covalently bind, adsorb or entrap other dietary components during transit along the gastrointestinal tract (GIT), and this capacity can also explain the changes in fermentation patterns as well as the FA flows in the $\mathrm{GIT}^{(6)}$. Furthermore, agro-industrial co-products may contain TAG (neutral fats) and phospholipids embedded within their fibre matrices. The fibrebound lipids may inevitably impose confounding effects that makes it difficult to understand the role played by added fats. Supplementary lipid sources include animal fats such as beef tallow that are rich in SFA or plant oils such as maize oil that are rich in unsaturated $\mathrm{FA}^{(5)}$. Unlike the cereal co-products that are

Abbreviations: ACD, apparent caecal digestibility; AID, apparent ileal digestibility; ATTD, apparent total tract digestibility; BA, bile acid; BW, body weight; DF, dietary fibre; FA, fatty acid; GIT, gastrointestinal tract; TFA, total fatty acids.

* Corresponding author: C. M. Nyachoti, fax +1 204474 7628, email Martin_Nyachoti@umanitoba.ca

$\dagger$ Deceased. 
rich in cellulose and have relatively minimal amounts of pectin, co-products from fruits, protein rich or oil-seed meals contain relatively high levels of pectin polysaccharides ${ }^{(1,2)}$. In this respect, the plant cell wall structure in co-products is made up of a network of cellulose fibrils and hemicellulose embedded in a network of pectins ${ }^{(1,2,6)}$, however, the relative proportions of these DF constituents also vary in natural sources of fibre. The latter confers plasticity and controls porosity of the cell wall, whereas the former functions as a load-bearing structure ${ }^{(6)}$. Thus, we suggested that the use of purified sources of DF such as cellulose and pectin that are lipid-free and well-characterised models for insoluble dietary fibre (IDF) and soluble dietary fibre (SDF), respectively, would open the way for investigating the interaction between DF and lipid types, by eliminating the confounding effects that may be imposed by the fibre matricebound lipids. SDF are highly fermentable and believed to influence the digestion process in the stomach and small intestines, whereas IDF primarily modulate processes in the caecum and colon where, due to their physical presence, they effectively increase faecal bulk, dilute hindgut contents and increase mouth to anus passage rate ${ }^{(1,6)}$. Thus, pectin and cellulose were regarded as soluble and insoluble fibre sources, respectively, and were used in this trial to create different conditions in different segments of the GIT. The addition of DF beyond optimum inclusion level may constrain feed intake or reduce digestibility of dietary components at a magnitude that depends on the source or the fermentability of the DF source or its ability to change digestion and alter different conditions in each segment of the GIT ${ }^{(1,6,7)}$. Taken together, the addition of DF-rich co-products may not only reduce feed cost but promote DF fermentation and modulate gastrointestinal health benefits and performance by modifying the gastrointestinal milieu, microbiota and nutrient absorption ${ }^{(6-11)}$.

In ruminants, it is well established that high-fat diets can inhibit DF fermentation by gastrointestinal microbiota ${ }^{(12)}$ or reduce microbiota population ${ }^{(13)}$ and diversity. The idiosyncrasy of the interaction between DF and lipid type on performance and gastrointestinal fermentation in pigs has been associated with microbial activity. Therefore, it can be postulated that the response of pigs to supplemented lipids in highfibre diets is greatly influenced by the inclusion level of DF and/ or its solubility. In pigs, soluble fibre is mostly fermented before reaching the colon but insoluble fibre is highly fermented after passing the caecum ${ }^{(14)}$. The diverse physicochemical properties of added lipids as well as their potential interactions with different types or sources of DF, minerals and microbiological activity may affect how fibre fermentation changes the conditions in different regions of the GIT and consequently the utilisation of added lipids in pigs. A common assumption is that SCFA (major products and indicators of fermentation) are rapidly absorbed and/or metabolised in the GIT. However, it is peculiar that the consumption of highly fermentable DF in pigs not only increased hindgut SCFA production and flows but also increased the amount of faecal fat and excretion of bile acids $(\mathrm{BA})^{(15-17)}$. It is still a matter of debate on whether faecal fat could be attributable to endogenous losses from the gastrointestinal secretions, microbial FA production or sub-optimal absorption of added lipids predisposed by encapsulation of FA within the DF matrices or by deconjugation of $\mathrm{BA}^{(16-20)}$. Increased faecal fat excretion because of fibre fermentation or poor fermentation of DF due to added lipids is obviously counter-productive of fibre nutrition efforts. There is need, therefore, to characterise and/or estimate the FA flows in each segment of the GIT as this may indicate FA that originates from malabsorption of added lipids, microbial activities or endogenous secretions. Understanding the role played by different sources of DF in creating different conditions in the GIT and subsequently modulating gastrointestinal fermentation characteristics and intestinal FA flows opens ways for formulation of high-fibre diets that optimise growth performance with minimum nutrient losses. Furthermore, this study could enhance the development of fundamental knowledge on how interaction of DF solubility and lipid type modulate pig performance and lipid nutrition. This is important to develop nutritional interventions to optimise dietary inclusion of high-fibre co-products as lowcost ingredients with desirable functional properties.

To the best of our knowledge, this study is the first to use ileal and caecal cannulated pigs to investigate the interactive effects of DF sources and degree of saturation of FA in supplementary lipids on digestibility of FA and FA flows in the ileum, caecum and the entire GIT. The hypothesis tested in this study was that dietary inclusion of either cellulose or pectin will create different conditions in the GIT, thereby modulating FA digestibility and gastrointestinal flow of FA, depending on the source of dietary lipids. Thus, the objective of the current study was to determine the interactive effects of DF type and source of dietary lipids on FA flows and the digestibility of dietary components in the ileum, caecum and the entire GIT using ileal and caecal cannulated pigs that were fed cellulose- or pectin-containing diets with either maize oil or beef tallow supplementation.

\section{Methods}

The experimental procedures and use of pigs in this trial were approved by the Animal Care Committee of the University of Guelph (protocol no. 1938). Pigs were cared for according to the guidelines of the Canadian Council on Animal Care ${ }^{(21)}$.

\section{Pigs and housing}

In brief, a total of eight Yorkshire barrows (25.3 (SD 1.67) kg mean body weight (BW)) were housed individually in pens $(1.2 \times 1.8 \mathrm{~m})$. The temperature in the room was maintained at $22 \pm 2 \cdot 3^{\circ} \mathrm{C}$ with a $14 \mathrm{~h}$ light and $10 \mathrm{~h}$ dark cycle. After a $7 \mathrm{~d}$ adaptation period to experimental room, pigs were surgically equipped with two simple T-cannulas. Before surgeries, pigs were injected with a Primix (carprofen $(2 \mathrm{mg} / \mathrm{kg} \mathrm{BW} ; 50 \mathrm{mg} / \mathrm{ml}$ ), Excenel (0.06 ml/kg BW; $100 \mathrm{mg} / \mathrm{ml}$; Excenel ${ }^{\circledR}$ RTU EZ, ceftiofur hydrochloride, sterile suspension; Zoetis Inc.), bupivacaine $(2 \mathrm{ml} / 25 \mathrm{~kg} \mathrm{BW})$ and buprenorphine $(0.01 \mathrm{mg} / \mathrm{kg} \mathrm{BW} ; 0.3 \mathrm{mg} / \mathrm{ml})$ to prevent pain and infections. The first cannula was inserted at the terminal ileum ${ }^{(22)}$ and the second cannula was placed in the caecum approximately $5 \mathrm{~cm}$ proximal to the caecocolic junction. The ileal and caecal cannulated pig model was used in this study because it opens ways for collecting ileal and caecal 
Table 1. Ingredients and analysed compositions $(\mathrm{g} / \mathrm{kg})$ of the experimental diets

\begin{tabular}{|c|c|c|c|c|}
\hline \multirow[b]{2}{*}{ Item } & \multicolumn{2}{|c|}{ Cellulose } & \multicolumn{2}{|c|}{ Pectin } \\
\hline & Maize oil & Beef tallow & Maize oil & Beef tallow \\
\hline \multicolumn{5}{|l|}{ Ingredients } \\
\hline Maize starch & 350 & 348 & 350 & 348 \\
\hline Casein & 135 & 135 & 135 & 135 \\
\hline Cellulose & 150 & 150 & - & - \\
\hline Pectin & - & - & 150 & 150 \\
\hline Sucrose & 267 & 267 & 267 & 267 \\
\hline Beef tallow & - & $63 \cdot 7$ & - & $63 \cdot 7$ \\
\hline Maize oil & $62 \cdot 0$ & - & $62 \cdot 0$ & - \\
\hline Limestone & 6.50 & 6.50 & $6 \cdot 50$ & $6 \cdot 50$ \\
\hline Monocalcium phosphate & $15 \cdot 00$ & $15 \cdot 00$ & $15 \cdot 00$ & $15 \cdot 00$ \\
\hline Salt & 3.50 & 3.50 & 3.50 & 3.50 \\
\hline Vitamin-mineral premix ${ }^{*}$ & 5.00 & 5.00 & 5.00 & 5.00 \\
\hline Lys & 0.85 & 0.85 & 0.85 & 0.85 \\
\hline DL-Met & 1.56 & 1.56 & 1.56 & 1.56 \\
\hline Thr & 1.05 & 1.05 & 1.05 & 1.05 \\
\hline Titanium dioxide & 3.00 & 3.00 & 3.00 & 3.00 \\
\hline \multicolumn{5}{|l|}{ Analysed compositions } \\
\hline DM & 931 & 931 & 931 & 931 \\
\hline Crude protein & 125 & 125 & 127 & 126 \\
\hline $\mathrm{Ca}$ & 6.9 & $6 \cdot 9$ & 6.9 & $6 \cdot 8$ \\
\hline $\mathrm{P}$ & 4.6 & 4.6 & 4.6 & 4.6 \\
\hline Diethyl ether extract & $65 \cdot 0$ & $67 \cdot 1$ & $62 \cdot 9$ & 67.5 \\
\hline Starch & 351 & 350 & 349 & 351 \\
\hline Total fatty acids & $72 \cdot 8$ & 73.3 & $72 \cdot 6$ & 73.1 \\
\hline \multicolumn{5}{|l|}{$\mathrm{NSP}(\mathrm{mg} / \mathrm{g})$} \\
\hline Galactose & - & - & 3.23 & 3.13 \\
\hline Glucose & 110 & 109 & $25 \cdot 0$ & 24.6 \\
\hline Mannose & 6.04 & 6.09 & - & - \\
\hline Xylose & $17 \cdot 6$ & $17 \cdot 7$ & - & - \\
\hline Uronic acids & 0.39 & 0.41 & $70 \cdot 9$ & 71.6 \\
\hline Total NSP & 134 & 134 & $99 \cdot 1$ & 98.8 \\
\hline
\end{tabular}

* Vitamin-mineral premix provided the following nutrients (per kg of air-dry diet): vitamin $A, 0.60 \mathrm{mg}$; vitamin $D_{3}, 0.01 \mathrm{mg} ;$ vitamin $E$, $40 \mathrm{mg}$; vitamin K, $2 \mathrm{mg}$; vitamin $\mathrm{B}_{1}, 1.5 \mathrm{mg}$; vitamin $\mathrm{B}_{2}, 7 \mathrm{mg}$; vitamin $\mathrm{B}_{6}, 2.5 \mathrm{mg}$; vitamin $\mathrm{B}_{12}, 25 \mu \mathrm{g}$; calcium pantothenate, $14 \mathrm{mg}$; folic acid, $1 \mathrm{mg}$; niacin, $21 \mathrm{mg}$ and biotin, $70 \mu \mathrm{g}$. Minerals: $\mathrm{Cu}, 10 \mathrm{mg}$ (as copper sulphate); iodine, $0.4 \mathrm{mg}$ (as potassium iodine); Fe, $120 \mathrm{mg}$ (as ferrous sulphate); Mn, $10 \mathrm{mg}$ (as manganous oxide); Se, $0.3 \mathrm{mg}$ (as sodium selenite) and $\mathrm{Zn}, 110 \mathrm{mg}$ (as zinc oxide).

digesta separately to assess fermentation of DF and FA flows in the uppergut, caecum and colorectal tract. During and after the surgery and recovery period, welfare-related assessments such as body temperature, feeding and general behaviour were conducted and recorded for each pigs. After surgery, pigs were allowed a recovery period of $10 \mathrm{~d}$. During the recovery period, the cannulated pigs were given Metacam $(0.4 \mathrm{mg} / \mathrm{kg} ; 15 \mathrm{mg} / \mathrm{ml}$; Metacam ${ }^{\circledR}$ for Swine; Boehringer Ingelheim) oral suspension for swine to control inflammation and pain. The areas around the cannulas were cleaned twice a day with an antiseptic soap and a zinc oxide cream was applied to prevent pain and infection. Each pen was equiped with welfare-enrichment toys and chains to improve the welfare conditions of the pigs. All pigs were healthy and finished their daily feed allowances.

\section{Experimental diets, design and management procedures}

The pigs were fed high-fibre diets that were formulated to contain $150 \mathrm{~g} / \mathrm{kg}$ of either cellulose (Cellulose powder BH65 FCC; Cambrian Chemicals Inc.) or pectin (Citrus pectin, GENU ${ }^{\circledR}$ pectin type VIS; CP Kelco) and either $62 \mathrm{~g} / \mathrm{kg}$ of maize oil or $63.7 \mathrm{~g} / \mathrm{kg}$ of beef tallow. In each diet, either pectin or cellulose was the only source of DF. Either maize oil or beef tallow was added in each diet, as the only source of dietary FA. Thus, giving a $2 \times 2$ factorial arrangement of treatments. The diets were formulated to meet nutrient requirements of growing pigs, as prescribed by the National Research Council (NRC) ${ }^{(23)}$ (Table 1). Titanium dioxide was included $(3.0 \mathrm{~g} / \mathrm{kg})$ as an indigestible marker in all diets.

A total of eight pigs were used in two blocks, four pigs per block. In each block, pigs were randomly assigned to the diets in a Youden square design with four treatments (diets), three columns (experimental periods) and four rows (pigs), to give six replicates per treatment ( $n$ 6). Pigs were weighed at the beginning of each experimental period and offered a daily feed ration equivalent to supply $2 \cdot 8$ times the estimated requirement for maintenance energy (i.e. $197 \mathrm{kcal}(824 \mathrm{~kJ})$ metabolisable energy $/ \mathrm{BW}^{0 \cdot 6} \mathrm{~kg}$; $\left.\mathrm{NRC}^{(23)}\right)$. The daily feed ration was offered in two equal meals at 08.00 and 20.00 hours. Pigs were offered feed that was mixed with water $(1: 2$, or $500 \mathrm{~g}$ of feed/l (w/v)) to improve palatability. All pigs finished their daily feed allowance throughout the experiment.

Each experimental period lasted $15 \mathrm{~d}$ : $9 \mathrm{~d}$ for acclimatisation to the experimental diets, followed by $2 \mathrm{~d}$ for faecal, $2 \mathrm{~d}$ for caecal contents and $2 \mathrm{~d}$ for ileal digesta collection. Using the grab sample technique, fresh faecal samples were collected hourly and placed into plastic bags and immediately frozen at $-20^{\circ} \mathrm{C}$. Ileal and caecal digesta were collected from each pig by 
attaching a sterile $500 \mathrm{ml}$ plastic bag to the cannula barrel. Digesta and faecal samples were collected over a $12 \mathrm{~h}$ period between 08.00 and 20.00 hours. However, throughout the sample collection period, plastic bags were filled with $10 \mathrm{ml}$ of $10 \%$ formic acid. The bags were changed every $30 \mathrm{~min}$ unless filled with digesta. After collection, digesta and faecal samples were thawed to semi-solid state, pooled within pig and collection period, freeze-dried and stored at $-80^{\circ} \mathrm{C}$ until analysed.

\section{Laboratory analysis}

The diets, faeces, ileal and caecal digesta were analysed (Table 2) in duplicates for DM, starch and ash following standard procedures ${ }^{(24)}$, and titanium as described by Lomer et $a{ }^{(25)}$. Total starch was determined using a test kit (Megazyme International Ireland). The diets were also analysed for crude protein, gross energy, diethyl ether extract, Ca, P, NSP contents as described by Ndou et al. ${ }^{(17)}$. Lipids were extracted from diets, digesta and faeces using a 2:1 chloroform-methanol mixture $^{(26)}$ and methylated to produce FA methyl esters ${ }^{(27)}$. All FA from C8:0 to C24:1 were analysed using GC but only specific FA present in high concentration were reported.

\section{Calculations and statistical analyses}

lodine values of diets. The iodine values (IV) and iodine value of the product (IVP) of the experimental diets were calculated as follows:

$\mathrm{IV}=((\mathrm{C} 16: 1) \times 0.95)+((\mathrm{C} 18: 1) \times 0 \cdot 86)+((\mathrm{C} 18: 2) \times 1 \cdot 732)+$ $((\mathrm{C} 18: 3) \times 2 \cdot 616)+((\mathrm{C} 20: 1) \times 0 \cdot 785)+((\mathrm{C} 22: 1) \times 0 \cdot 723), \quad$ in which the brackets indicate concentration (percentage) of FA (adopted from American Oil Chemists' Society ${ }^{(28)}$ ).

IVP $=($ IV of dietary lipids $) \times(\%$ dietary lipid $) \times 0 \cdot 10$ (adopted from Madsen et al. $\left.{ }^{(29)}\right)$.

Digestibility and flows. The apparent ileal digestibility (AID), apparent caecal digestibility (ACD) and apparent total

Table 2. Fatty acid profile ( $\mathrm{g} / 100 \mathrm{~g}$ of total fatty acids) of experimental diets

\begin{tabular}{|c|c|c|c|c|}
\hline \multirow[b]{2}{*}{ Item } & \multicolumn{2}{|c|}{ Cellulose } & \multicolumn{2}{|c|}{ Pectin } \\
\hline & Maize oil & Beef tallow & Maize oil & Beef tallow \\
\hline Caprylic acid $(8: 0)$ & 0.01 & 0.01 & 0.01 & 0.01 \\
\hline Capric acid $(10: 0)$ & 0.05 & 0.07 & 0.06 & 0.08 \\
\hline Lauric acid $(12: 0)$ & 0.09 & 0.20 & 0.09 & 0.20 \\
\hline Myristic acid $(14: 0)$ & 0.36 & 1.49 & 0.40 & 1.52 \\
\hline Myristoleic acid (14:1) & 0.02 & $0 \cdot 18$ & 0.02 & 0.16 \\
\hline Pentadecyclic acid $(15: 0)$ & 0.06 & 0.20 & 0.07 & 0.20 \\
\hline Palmitic acid $(16: 0)$ & 12.95 & 20.58 & 12.89 & 20.89 \\
\hline Palmitelaidic acid $(16: 1 t)$ & 0.05 & 0.23 & 0.05 & 0.25 \\
\hline Palmitoleic acid $(16: 1 n-7)$ & 0.10 & $2 \cdot 28$ & 0.14 & $2 \cdot 27$ \\
\hline Margaric acid $(17: 0)$ & 0.10 & 0.43 & $0 \cdot 10$ & 0.44 \\
\hline Stearic acid $(18: 0)$ & 1.84 & 11.07 & 1.89 & 11.48 \\
\hline Oleic acid $(18: 1 n-9)$ & $26 \cdot 79$ & 41.86 & $26 \cdot 69$ & 41.51 \\
\hline Vaccenic acid $(18: 1 n-7)$ & 0.35 & 1.90 & 0.51 & 1.74 \\
\hline Linoleic acid $(18: 2)$ & 55.45 & $15 \cdot 85$ & $55 \cdot 29$ & $15 \cdot 54$ \\
\hline Linolenic acid $(18: 3 n-6)$ & 0.00 & 0.04 & 0.00 & 0.04 \\
\hline$a$-Linolenic acid $(18: 3 n-3)$ & 0.83 & 1.99 & 0.83 & $2 \cdot 01$ \\
\hline Arachidic acid $(20: 0)$ & 0.39 & 0.26 & 0.38 & 0.27 \\
\hline Gadoleic acid (20:1) & 0.29 & 0.59 & 0.34 & 0.62 \\
\hline Eicosadienoic acid $(20: 2)$ & 0.02 & 0.22 & 0.02 & 0.23 \\
\hline Dihomo- $\gamma$-linolenic acid $(20: 3 n-6)$ & 0.00 & 0.05 & 0.00 & 0.06 \\
\hline Eicosatrienoic acid $(20: 3 n-3)$ & 0.01 & 0.05 & 0.01 & 0.05 \\
\hline Arachidonic acid $(20: 4 n-6)$ & 0.00 & 0.19 & 0.00 & 0.17 \\
\hline EPA $(20: 5 n-3)$ & 0.01 & 0.01 & 0.02 & 0.01 \\
\hline Behenic acid $(22: 0)$ & 0.11 & 0.09 & 0.09 & 0.09 \\
\hline Erucic acid $(22: 1 n-9)$ & 0.01 & 0.01 & 0.00 & 0.01 \\
\hline Docosatetraenoic acid $(22: 4 n-6)$ & 0.13 & 0.04 & $0 \cdot 12$ & 0.04 \\
\hline Osbond acid $(22: 5 n-6)$ & 0.01 & 0.02 & 0.01 & 0.02 \\
\hline Docosapentaenoic acid (22:5n-3) & 0.00 & 0.04 & 0.00 & 0.03 \\
\hline DHA $(22: 6 n-3)$ & 0.00 & 0.01 & 0.00 & 0.01 \\
\hline Lignoceric acid $(24: 0)$ & 0.13 & 0.03 & $0 \cdot 12$ & 0.04 \\
\hline Nervonic acid $(24: 1 n-9)$ & 0.00 & 0.04 & 0.00 & 0.03 \\
\hline$\sum \mathrm{SFA}^{*}$ & $16 \cdot 08$ & $34 \cdot 41$ & $16 \cdot 09$ & $35 \cdot 23$ \\
\hline $\bar{\Sigma}$ UFA† & 83.92 & 65.59 & 83.91 & 64.77 \\
\hline$\sum$ MUFA & 27.59 & 47.09 & $27 \cdot 74$ & 46.57 \\
\hline$\sum$ PUFA§ & $56 \cdot 33$ & $18 \cdot 50$ & $56 \cdot 17$ & $18 \cdot 20$ \\
\hline Calculated IV (g/100 g) & 122 & 71 & 121 & 71 \\
\hline Calculated IVP (g/100 g) & 88 & 52 & 89 & 52 \\
\hline
\end{tabular}

IV iodine value; IVP, iodine value of the product.

* $\sum$ SFA $=$ total SFA

$\dagger \sum$ UFA $=$ total unsaturated fatty acids.

$\ddagger \sum$ MUFA $=$ total MUFA.

$\S \sum$ PUFA $=$ total PUFA 
tract digestibility (ATTD) digestibilities were calculated as follows:

$$
\begin{aligned}
& \text { Apparent digestibility }(\%) \\
& =\left(1-\left(\left(\text { Nutrient }_{\mathrm{F} / \mathrm{C} / \mathrm{I}} \div \text { Nutrient }_{\mathrm{D}}\right) \times\left(T_{\mathrm{D}} \div \mathrm{F} / \mathrm{C} / \mathrm{I}\right)\right)\right) \times 100
\end{aligned}
$$

where Nutrient $\mathrm{F}_{\mathrm{F} / \mathrm{C} / \mathrm{I}}$ are the contents of dietary components $(\mathrm{g} / \mathrm{kg} \mathrm{DM})$ in the faeces (F), caecal (C) or ileal (I) digesta, respectively; Nutrient ${ }_{\mathrm{D}}$ is the content of each nutrient $(\mathrm{g} / \mathrm{kg} \mathrm{DM})$ in the diet; $T_{\mathrm{D}}$ is the titanium dioxide $(\mathrm{g} / \mathrm{kg} \mathrm{DM})$ in the diet and $T_{\mathrm{F} / \mathrm{C} / \mathrm{I}}$ are the concentrations of titanium dioxide $(\mathrm{g} / \mathrm{kg} \mathrm{DM})$ in faeces, caecal or ileal digesta, respectively.

The flow of FA in the stomach and small intestines, caecum or colon was calculated using the following equation:

$$
\text { Flow }_{\text {nutrient }}(\mathrm{g} / \mathrm{kg} \text { DMintake })=\text { Nutrient }_{\mathrm{F} / \mathrm{C} / \mathrm{I}} \times\left(\mathrm{T}_{\mathrm{D}} \div \mathrm{T}_{\mathrm{F} / \mathrm{C} / \mathrm{I}}\right),
$$

where Flow $_{\text {nutrient }}$ is the flow of dietary components; Nutrient $_{\mathrm{I} / \mathrm{C} / \mathrm{F}}$ is the concentration of each dietary component in faeces (F), ileal (I) or caecal (C) digesta, respectively.

Statistical analyses. Statistical analyses were performed using SAS (version 9.4, 2009; SAS Institute Inc.) ${ }^{(30)}$. A power test analysis estimated according to Bowley ${ }^{(31)}$ and based on data obtained from a recent study ${ }^{(14)}$ on digestibility and flows of dietary components in ileal- and caecal-cannulated pigs was performed to determine the number of replicates per treatment needed for the present experiment. On the basis of the same effect size, the power test analysis indicated that statistical power of more than $90 \%$ for a sample size of six and $\alpha=0.05$ could be expected, enabling adequate power to reject the null hypothesis when it is false $(P=1-\beta)$. In this regard, our proposed sample size of six replicates per treatment may provide more power when considering multiple comparisons.

The data were analysed as a completely randomised design with $2 \times 2$ factorial treatment arrangements using the GLIMMIX procedure. The models accounted for the main effects of DF and lipid types and associated two-way interactions as fixed factors. The pig, block and period were included as random effects. The pig (nested within period) was considered as the experimental unit for all analyses. A total of three contrast statements were also tested to compare the effect of DF source (cellulose $v$. pectin), lipid type (maize oil $v$. beef tallow) and the interactions of DF and lipid types. Comparisons of means for the interactions between DF and lipid types were performed using the TukeyKramer honestly significance difference test. A $P$-value of $\leq 0.05$ was used to determine significance, and trends declared for $P$-values between $0 \cdot 05$ and $0 \cdot 10$ were discussed.

\section{Results}

All pigs consumed their assigned diets without refusals or spillages and faecal, caecal and ileal digesta samples were successfully collected from all pigs.

\section{Apparent ileal digestibility and fermentability}

There were interactions $(P<0 \cdot 05$, Table 3$)$ between $\mathrm{DF}$ and lipid types on AID of DM, SFA, MUFA, PUFA and total fatty acids (TFA). In this regard, the addition of beef tallow increased

\begin{tabular}{|c|c|c|c|c|c|c|c|c|}
\hline \multirow[b]{2}{*}{ Item } & \multicolumn{2}{|c|}{ Cellulose } & \multicolumn{2}{|c|}{ Pectin } & \multirow[b]{2}{*}{ SEM } & \multicolumn{3}{|c|}{$P+$} \\
\hline & Maize oil & Beef tallow & Maize oil & Beef tallow & & Fibre & Lipid & $\mathrm{F} \times \mathrm{L}$ \\
\hline \multicolumn{9}{|c|}{ Apparent ileal digestibility } \\
\hline DM & $52 \cdot 6^{b}$ & $52 \cdot 0^{b}$ & $56 \cdot 0^{b}$ & $61 \cdot 7^{\mathrm{a}}$ & $2 \cdot 26$ & $<0.001$ & 0.348 & 0.025 \\
\hline $\mathrm{N}$ & 94.8 & 90.5 & $90 \cdot 7$ & $95 \cdot 1$ & 2.07 & 0.856 & 0.429 & 0.146 \\
\hline Starch & 94.0 & $94 \cdot 3$ & $90 \cdot 2$ & 91.9 & $2 \cdot 17$ & 0.041 & 0.726 & 0.301 \\
\hline SFA & $70 \cdot 7^{c}$ & $75 \cdot 0^{b}$ & $72 \cdot 3^{c}$ & $80 \cdot 6^{a}$ & 1.07 & $<0.001$ & 0.546 & 0.031 \\
\hline MUFA & $90 \cdot 7^{a}$ & $87 \cdot 3^{b}$ & $86 \cdot 5^{b}$ & $91.9^{a}$ & $1 \cdot 24$ & 0.071 & 0.078 & 0.001 \\
\hline PUFA & $80 \cdot 7^{c}$ & $85 \cdot 3^{b}$ & $79 \cdot 1^{c}$ & $90 \cdot 6^{a}$ & 1.57 & $<0.001$ & 0.111 & $<0.001$ \\
\hline TFA & $95 \cdot 8^{a}$ & $96 \cdot 0^{a}$ & $89 \cdot 4^{b}$ & $85 \cdot 1^{c}$ & 1.23 & 0.047 & 0.246 & 0.028 \\
\hline \multicolumn{9}{|c|}{ Apparent caecal digestibility } \\
\hline DM & $57 \cdot 6$ & $57 \cdot 0$ & 58.9 & $60 \cdot 0$ & $1 \cdot 10$ & 0.035 & 0.511 & 0.063 \\
\hline $\mathrm{N}$ & $96 \cdot 8$ & $90 \cdot 5$ & $90 \cdot 7$ & 94.9 & $2 \cdot 27$ & 0.071 & 0.633 & 0.211 \\
\hline Starch & $93 \cdot 7$ & $92 \cdot 4$ & $93 \cdot 3$ & 94.4 & 2.85 & 0.064 & 0.062 & 0.689 \\
\hline SFA & $78 \cdot 7^{\mathrm{c}}$ & $92 \cdot 4^{\mathrm{a}}$ & $89 \cdot 3^{b}$ & $79 \cdot 1^{c}$ & 0.41 & 0.021 & 0.912 & 0.001 \\
\hline MUFA & $93 \cdot 7^{a}$ & $82 \cdot 7^{b}$ & $84 \cdot 6^{b}$ & $94 \cdot 4^{\mathrm{a}}$ & 2.04 & $<0.001$ & 0.878 & 0.001 \\
\hline PUFA & $89 \cdot 0$ & $95 \cdot 1$ & $88 \cdot 1$ & $89 \cdot 1$ & 4.65 & 0.054 & 0.012 & 0.073 \\
\hline TFA & $94 \cdot 8^{\mathrm{a}}$ & $72 \cdot 7^{c}$ & $88 \cdot 5^{b}$ & $87 \cdot 1^{b}$ & 1.57 & 0.001 & 0.311 & 0.041 \\
\hline \multicolumn{9}{|c|}{ Apparent total tract digestibility } \\
\hline DM & $72 \cdot 3^{a}$ & $68 \cdot 4^{b}$ & $74 \cdot 2^{\mathrm{a}}$ & $71 \cdot 8^{\mathrm{a}, \mathrm{b}}$ & $1 \cdot 38$ & $<0.001$ & 0.581 & $<0.001$ \\
\hline $\mathrm{N}$ & $95 \cdot 6$ & $93 \cdot 0$ & $92 \cdot 2$ & $95 \cdot 1$ & $5 \cdot 73$ & 0.384 & 0.564 & 0.373 \\
\hline Starch & $95 \cdot 6$ & $93 \cdot 1$ & 93.7 & 95.9 & $6 \cdot 72$ & 0.248 & 0.932 & 0.674 \\
\hline SFA & 80.5 & $74 \cdot 2$ & $76 \cdot 1$ & $80 \cdot 7$ & 4.44 & 0.086 & 0.976 & 0.606 \\
\hline MUFA & $90 \cdot 6$ & $93 \cdot 1$ & $93 \cdot 7$ & 91.9 & 4.05 & 0.396 & 0.878 & 0.151 \\
\hline PUFA & $90 \cdot 5^{a}$ & $84 \cdot 2^{b}$ & $86 \cdot 1^{b}$ & $90 \cdot 6^{a}$ & $1 \cdot 12$ & $<0.001$ & 0.076 & 0.041 \\
\hline TFA & 94.6 & $94 \cdot 3$ & 86.9 & $85 \cdot 1$ & 3.57 & $<0.001$ & 0.976 & 0.181 \\
\hline
\end{tabular}

Table 3. Apparent ileal, caecal and total tract digestibility (\%) of dietary components by growing pigs fed experimental diets* (Mean values with their standard errors)

TFA, total fatty acids

a,b,c Mean values within a row with unlike superscript letters were significantly different $(P<0.05)$

* Mean values with their pooled standard errors ( $n 6$ per treatment).

$\dagger$ Contrast statements: fibre $=$ cellulose $v$. pectin; lipid $=$ maize oil $v$. beef tallow; $F \times L=$ interaction of dietary fibre and lipid type. 
$(P<0.05)$ the AID of DM in the pectin-containing diet but did not induce effects in the diet with cellulose. Dietary supplementation with beef tallow increased $(P<0.05)$ the AID of SFA and PUFA in both pectin- and cellulose-containing diets. The addition of beef tallow reduced the AID of MUFA $(P=0 \cdot 001)$ in the cellulose-containing diet but increased in the pectincontaining diet. Dietary supplementation with beef tallow decreased $(P<0.05)$ the AID of TFA in the pectin-containing diet but did not have effects in the cellulose-containing diet. There were no significant interactive effects of DF and lipid types on AID of $\mathrm{N}$ and starch, but the main effects of DF increased the AID of starch in cellulose-containing diets $(P<0.05)$ compared with pectin-containing diets.

\section{Apparent caecal digestibility and fermentability}

There was an interaction $(P<0.05$; Table 3$)$ between DF and lipid types on the ACD of SFA, MUFA and TFA. The addition of beef tallow increased the ACD of SFA in cellulose-containing diets but decreased in diets containing pectin $(P=0.001)$. Supplementary beef tallow decreased the ACD of MUFA in the diet containing cellulose but increased in the pectin-containing diet $(P<0.05)$. Dietary addition of beef tallow decreased $(P<0.05)$ the ACD of TFA in cellulose-containing diets but did not induce effects in pectin-containing diets. There were no

Table 4. Ileal fatty acid flow in pigs fed experimental diets ( $\mathrm{mg} / \mathrm{kg}$ DM intake)*

(Mean values with their standard errors) interactions $(P>0.05)$ between DF and lipid types on ACD of DM, N, starch and PUFA, however, the main effects of DF were such that diets containing pectin had greater $(P<0.05)$ ACD of DM compared to diets containing cellulose. The main effects of dietary lipid type increased the ACD of PUFA in diets supplemented with beef tallow compared with diets containing supplementary maize oil $(P<0 \cdot 05)$.

\section{Apparent total tract digestibility and fermentability}

An interaction $(P<0.05)$ of DF and lipid type was observed on ATTD of DM and PUFA but not $(P>0.05)$ on ATTD of N, starch, SFA, MUFA and TFA (Table 3 ). In this regard, the addition of beef tallow decreased $(P<0.001)$ the ATTD of DM in the cellulose-containing diet but did not have effects in pectincontaining diets. Dietary supplementation with beef tallow decreased the ATTD of PUFA $(P<0.01)$ in cellulose-containing diets but increased in diets containing pectin. The main effects of DF type decreased the $(P<0 \cdot 001)$ ATTD of TFA in pectincontaining diets compared with cellulose-containing diets.

\section{Fatty acid flows in the ileum}

There were interactions $(P<0.05$; Table 4) between DF and lipid types on the ileal flow of $8: 0,16: 1 t, 16: 1 n-7,18: 0$,

\begin{tabular}{|c|c|c|c|c|c|c|c|c|}
\hline \multirow[b]{2}{*}{ Item } & \multicolumn{2}{|c|}{ Cellulose } & \multicolumn{2}{|c|}{ Pectin } & \multirow[b]{2}{*}{ SEM } & \multicolumn{3}{|c|}{$P+$} \\
\hline & Maize oil & Beef tallow & Maize oil & Beef tallow & & Fibre & Lipid & $F \times L$ \\
\hline Caprylic acid (8:0) & $0.11^{\mathrm{c}}$ & $3 \cdot 88^{a}$ & $0.53^{\mathrm{b}}$ & $0.08^{c}$ & 0.146 & 0.001 & 0.015 & 0.023 \\
\hline Capric acid $(10: 0)$ & 0.00 & 0.02 & 0.01 & 0.00 & 0.007 & 0.846 & 0.429 & 0.111 \\
\hline Lauric acid (12:0) & 0.01 & 0.02 & 0.01 & 0.01 & 0.163 & 0.384 & 0.358 & 0.365 \\
\hline Myristic acid (14:0) & 0.11 & 0.26 & 0.17 & 0.17 & 0.159 & $<0.399$ & 0.456 & 0.155 \\
\hline Myristoleic acid (14:1) & 0.00 & 0.01 & 0.01 & 0.10 & 0.067 & 0.846 & 0.379 & 0.371 \\
\hline Pentadecyclic acid $(15: 0)$ & 0.01 & 0.01 & 0.02 & 0.02 & 0.004 & 0.071 & 0.878 & 0.364 \\
\hline Palmitic acid $(16: 0)$ & $9 \cdot 13$ & $12 \cdot 84$ & 13.92 & $12 \cdot 17$ & 3.010 & 0.186 & 0.596 & 0.372 \\
\hline Palmitelaidic acid (16:1t) & 1.60 & 2.73 & $7 \cdot 42$ & $9 \cdot 12$ & $2 \cdot 254$ & 0.043 & 0.633 & 0.124 \\
\hline Palmitoleic acid (16:1, n-7) & $0.05^{c}$ & $0.11^{\mathrm{c}}$ & $0 \cdot 20^{\mathrm{b}}$ & $0.50^{\mathrm{a}}$ & $0 \cdot 165$ & $<0.001$ & 0.258 & $<0.001$ \\
\hline Margaric acid (17:0) & 0.46 & 0.55 & 1.55 & 1.64 & 0.146 & 0.025 & 0.849 & 0.365 \\
\hline Stearic acid $(18: 0)$ & $1096 \cdot 6^{a}$ & $547 \cdot 8^{\mathrm{b}}$ & $875 \cdot 6^{a}$ & $407 \cdot 5^{\mathrm{b}}$ & 113.04 & $<0.001$ & 0.011 & 0.001 \\
\hline Oleic acid $(18: 1, n-9)$ & $284 \cdot 8^{d}$ & $771.0^{\mathrm{b}}$ & $648 \cdot 0^{\mathrm{C}}$ & $1137 \cdot 0^{\mathrm{a}}$ & $35 \cdot 18$ & $<0.001$ & 0.581 & $<0.001$ \\
\hline Vaccenic acid $(18: 1, n-7)$ & $14.53^{c}$ & $115 \cdot 71^{a}$ & $81 \cdot 38^{\mathrm{b}}$ & $130 \cdot 49^{a}$ & $12 \cdot 478$ & 0.011 & 0.034 & 0.043 \\
\hline Linoleic acid (18:2) & $8 \cdot 13^{\mathrm{C}}$ & $78 \cdot 27^{a}$ & $79 \cdot 18^{a}$ & $43.66^{b}$ & 6.545 & 0.031 & 0.777 & 0.001 \\
\hline Linolenic acid $(18: 3, n-6)$ & $0.08^{d}$ & $2.06^{b}$ & $1 \cdot 31^{\mathrm{c}}$ & $5 \cdot 21^{a}$ & 0.123 & 0.024 & 0.042 & 0.048 \\
\hline$a$-Linolenic acid $(18: 3, n-3)$ & $0.01^{b}$ & $0.03^{b}$ & $0.04^{\mathrm{b}}$ & $0.58^{a}$ & 0.234 & 0.024 & 0.682 & 0.079 \\
\hline Arachidic acid $(20: 0)$ & $0.44^{\mathrm{b}}$ & $1.03^{b}$ & $2.02^{a}$ & $1.06^{\mathrm{b}}$ & 0.354 & 0.083 & 0.094 & 0.024 \\
\hline Gadoleic acid $(20: 1)$ & $0.55^{d}$ & $3 \cdot 39^{a}$ & $2 \cdot 42^{\mathrm{b}}$ & $0.84^{c}$ & 3.22 & 0.045 & 0.406 & 0.153 \\
\hline Eicosadienoic acid (20:2) & $0.04^{\mathrm{c}}$ & $0 \cdot 15^{\mathrm{b}}$ & $0 \cdot 19^{b}$ & $0.38^{a}$ & 0.013 & $<0.001$ & 0.878 & 0.001 \\
\hline Dihomo- $\gamma$-linolenic acid $(20: 3, n-6)$ & 0.01 & 0.01 & 0.01 & 0.03 & 0.015 & 0.248 & 0.189 & 0.348 \\
\hline Eicosatrienoic acid $(20: 3, n-3)$ & $0.02^{b}$ & $0.04^{a}$ & $0.04^{a}$ & $0.04^{a}$ & 0.008 & 0.051 & 0.347 & 0.031 \\
\hline Arachidonic acid $(20: 4, n-6)$ & 0.01 & 0.03 & 0.03 & 0.04 & 0.005 & 0.365 & 0.956 & 0.073 \\
\hline EPA $(20: 5, n-3)$ & 0.01 & 0.02 & 0.01 & 0.01 & 0.004 & 0.489 & 0.564 & 0.095 \\
\hline Behenic acid (22:0) & 0.02 & 0.02 & 0.09 & 0.09 & 0.013 & $<0.001$ & 0.932 & 0.682 \\
\hline Erucic acid $(22: 1, n-9)$ & 0.10 & 0.05 & 0.12 & 0.02 & 0.072 & 0.745 & 0.792 & 0.244 \\
\hline Docosapentaenoic acid $(22: 5, n-6)$ & 0.08 & 0.11 & 0.08 & 0.05 & 0.064 & 0.024 & 0.682 & 0.129 \\
\hline $\mathrm{DHA}(22: 6, n-3)$ & 0.01 & 0.06 & 0.01 & 0.01 & 0.004 & 0.738 & 0.439 & 0.735 \\
\hline Lignoceric acid (24:0) & 0.05 & 0.13 & 0.10 & 0.02 & 0.273 & 0.003 & 0.964 & 0.324 \\
\hline Nervonic acid $(24: 1, n-9)$ & 0.25 & 0.17 & 0.20 & 0.06 & 0.165 & 0.739 & 0.159 & 0.685 \\
\hline
\end{tabular}

a,b,c,d Mean values within a row with unlike superscript letters were significantly different $(P<0.05)$.

${ }^{*}$ Mean values with their pooled standard errors ( $n 6$ per treatment).

$\dagger$ Contrast statements: fibre $=$ cellulose $v$. pectin; lipid $=$ maize oil $v$. beef tallow; $F \times L=$ interaction of dietary fibre and lipid type. 
$18: 1 n-9,18: 1 n-7,18: 2,18: 3 n-6,20: 0,20: 2$ and $20: 3 n-3$. Dietary supplementation with beef tallow increased the ileal flow of $8: 0$ and $18: 2$ in cellulose-containing diets but decreased in diets containing pectin $(P<0.05)$. Dietary supplementation with beef tallow increased $(P<0 \cdot 01)$ the flow of ileal $16: 1 n-7$ in pectin-containing diets but did have effects in cellulose-containing diets. Dietary inclusion of beef tallow decreased $(P=0 \cdot 001)$ the ileal flow of $18: 0$ in diets containing cellulose and pectin. The flow of $18: 1 n-9,18: 1 n-7,18: 3 n-6$ and $20: 2$ in the ileum increased $(P<0.05)$ with supplementation of beef tallow in both cellulose- and pectin-containing diets. The supplementation with beef tallow decreased the flow of 20:0 in the ileum in pectin-containing diets but did not have effects in the diet containing cellulose $(P<0.05)$. The addition of beef tallow increased $(P<0.05)$ the flow of $20: 3 n-3$ in ileum in cellulose-containing diets but did not induce effects in pectincontaining diets.

There were no $(P>0 \cdot 10)$ interactive effects of DF and lipids types in the ileal flows of $10: 0,12: 0,14: 0,14: 1,15: 0,16: 0$,

$16: 1 t, \quad 18: 3 n-3,20: 1,20: 3 n-6,20: 4 n-6,20: 5 n-3,22: 0$, $22: 1 n-9,22: 5 n-6,22: 6 n-3,24: 0$ and $24: 1 n-9$. The main effects of DF increased $(P<0.05)$ the ileal flow of $16: 1 t$ and $17: 0$ in pectin-containing diets compared with cellulosecontaining diets.

Table 5. Caecal fatty acid flow in pigs fed the experimental diets ( $\mathrm{mg} / \mathrm{kg} \mathrm{DM}$ intake)*

(Mean values with their standard errors)

\section{Fatty acid flows in the caecum}

In the caecum, an interaction $(P<0 \cdot 01$; Table 5$)$ of DF and lipid type was observed on the flows of $8: 0,10: 0,14: 0,14: 1,15: 0$, $16: 0,16: 1 t, 16: 1 n-7,17: 0,18: 0,18: 1 n-9,18: 1 n-7,18: 2$, $18: 3 n-6,18: 3 n-3,20: 0,20: 1,20: 2,20: 4 n-6,22: 0,22: 1 n-9$, $22: 5 n-3$ and $24: 1 n-9$. In this case, supplementary beef tallow increased $(P<0.05)$ the flows of $8: 0,10: 0,14: 0,14: 1,15: 0$, $16: 0, \quad 16: 1 t, 16: 1 n-7, \quad 17: 0,18: 1 n-7,18: 1 n-9,18: 3 n-3$, $18: 3 n-6,20: 1,20: 2,22: 0,22: 1 n-9$ and $22: 5 n-3$ in the caecum in diets containing pectin but did not have effects in cellulose-containing diets. The addition of beef tallow decreased $(P<0.05)$ the caecal flow of 18:0, 18:2, 20:0 and $20: 4 n-6$ in pectin-containing diets but did not have effects in cellulose-containing diets. The dietary supplementation with beef tallow decreased the flow of caecal $24: 1 n-9$ in both celluloseand pectin-containing diets. There were no significant interactive effects of DF and lipid types on the caecal flows of $12: 0$, $20: 3 n-6,20: 3 n-3,20: 5 n-3,22: 4 n-6,22: 6 n-3$ and $24: 0$.

\section{Flow of fatty acids in faeces}

There was an interaction $(P<0 \cdot 05$; Table 6$)$ between DF and lipid type on faecal flow of $8: 0,12: 0,14: 1,16: 1 t, 18: 2,20: 0$,

\begin{tabular}{|c|c|c|c|c|c|c|c|c|}
\hline \multirow[b]{2}{*}{ Item } & \multicolumn{2}{|c|}{ Cellulose } & \multicolumn{2}{|c|}{ Pectin } & \multirow[b]{2}{*}{ SEM } & \multicolumn{3}{|c|}{$P+$} \\
\hline & Maize oil & Beef tallow & Maize oil & Beef tallow & & Fibre & Lipid & $\mathrm{F} \times \mathrm{L}$ \\
\hline Caprylic acid (8:0) & $0.26^{b}$ & $0.22^{b}$ & $0.86^{b}$ & $11 \cdot 52^{a}$ & 3.658 & 0.086 & 0.595 & 0.042 \\
\hline Capric acid $(10: 0)$ & $0.01^{b}$ & $0.00^{b}$ & $0.01^{b}$ & $0.03^{a}$ & 0.008 & $<0.001$ & 0.296 & $<0.001$ \\
\hline Lauric acid (12:0) & 0.00 & 0.01 & 0.01 & 0.02 & 0.011 & 0.254 & 0.745 & 0.648 \\
\hline Myristic acid (14:0) & $0 \cdot 12^{b}$ & $0.09^{b}$ & $0 \cdot 18^{b}$ & $0.29^{a}$ & 0.054 & $<0.001$ & 0.878 & 0.001 \\
\hline Myristoleic acid (14:1) & $0.01^{b}$ & $0.01^{b}$ & $0.01^{b}$ & $0.63^{a}$ & 0.137 & 0.587 & 0.547 & $<0.001$ \\
\hline Pentadecyclic acid $(15: 0)$ & $0.01^{b}$ & $0.01^{b}$ & $0.01^{b}$ & $0.32^{\mathrm{a}}$ & 0.024 & 0.014 & 0.578 & 0.001 \\
\hline Palmitic acid $(16: 0)$ & $14 \cdot 1^{\mathrm{b}}$ & $13 \cdot 4^{\mathrm{b}}$ & $20 \cdot 0^{\mathrm{b}}$ & $33 \cdot 3^{a}$ & $4 \cdot 012$ & 0.301 & 0.383 & 0.041 \\
\hline Palmitelaidic acid $(16: 1 t)$ & $1.57^{\mathrm{C}}$ & $2 \cdot 04^{\mathrm{C}}$ & $8 \cdot 29^{b}$ & $19 \cdot 9^{a}$ & 2.66 & $<0.001$ & 0.228 & 0.011 \\
\hline Palmitoleic acid (16:1n-7) & $0.04^{c}$ & $0.03^{c}$ & $0 \cdot 16^{b}$ & $0.38^{a}$ & 0.085 & $<0.001$ & 0.972 & 0.033 \\
\hline Margaric acid $(17: 0)$ & $0.31^{c}$ & $0 \cdot 29^{c}$ & $0.60^{b}$ & $1 \cdot 15^{\mathrm{a}}$ & 0.146 & 0.061 & 0.695 & 0.010 \\
\hline Stearic acid $(18: 0)$ & $1287^{\mathrm{a}}$ & $1091^{a}$ & $750^{\mathrm{b}}$ & $585^{\mathrm{c}}$ & $120 \cdot 4$ & $<0.001$ & 0.878 & 0.001 \\
\hline Oleic acid $(18: 1 n-9)$ & $201^{c}$ & $346^{c}$ & $741^{\mathrm{b}}$ & $1116^{\mathrm{a}}$ & $139 \cdot 4$ & $<0.001$ & 0.041 & $<0.001$ \\
\hline Vaccenic acid (18:1n-7) & $14 \cdot 1^{\mathrm{b}}$ & $16 \cdot 0^{b}$ & $92 \cdot 8^{b}$ & $185^{a}$ & $28 \cdot 38$ & $<0.001$ & 0.564 & 0.003 \\
\hline Linoleic acid $(18: 2)$ & $10 \cdot 9^{c}$ & $7 \cdot 08^{c}$ & $136 \cdot 9^{a}$ & $54.5^{\mathrm{b}}$ & $16 \cdot 72$ & $<0.001$ & 0.932 & $<0.001$ \\
\hline Linolenic acid $(18: 3 n-6)$ & $0.03^{c}$ & $0.06^{c}$ & $1.39^{b}$ & $2.62^{a}$ & 0.416 & 0.024 & 0.635 & 0.029 \\
\hline$a$-Linolenic acid (18:3n-3) & $0.01^{b}$ & $0.01^{b}$ & $0.03^{b}$ & $0 \cdot 19^{a}$ & 0.064 & 0.534 & 0.286 & 0.039 \\
\hline Arachidic acid $(20: 0)$ & $0.35^{c}$ & $0.36^{c}$ & $2 \cdot 10^{\mathrm{a}}$ & $0.89^{b}$ & 0.173 & 0.003 & 0.357 & 0.024 \\
\hline Gadoleic acid $(20: 1)$ & $0.94^{c}$ & $0.88^{c}$ & $1.66^{\mathrm{b}}$ & $3.72^{a}$ & 0.222 & 0.045 & 0.406 & 0.043 \\
\hline Eicosadienoic acid $(20: 2)$ & $0.05^{c}$ & $0.07^{\mathrm{C}}$ & $0 \cdot 15^{b}$ & $0 \cdot 27^{a}$ & 0.034 & $<0.001$ & 0.878 & 0.001 \\
\hline Dihomo- $\gamma$-linolenic acid $(20: 3 n-6)$ & 0.01 & 0.01 & 0.02 & 0.02 & 0.033 & 0.245 & 0.668 & 0.175 \\
\hline Eicosatrienoic acid $(20: 3 n-3)$ & 0.01 & 0.01 & 0.05 & 0.03 & 0.018 & 0.012 & 0.511 & 0.123 \\
\hline Arachidonic acid $(20: 4 n-6)$ & $0.01^{c}$ & $0.01^{c}$ & $0.06^{\mathrm{a}}$ & $0.04^{b}$ & 0.011 & $<0.031$ & 0.581 & 0.001 \\
\hline EPA $(20: 5 n-3)$ & 0.01 & 0.01 & 0.01 & 0.01 & 0.012 & 0.121 & 0.478 & 0.313 \\
\hline Behenic acid (22:0) & $0.03^{b}$ & $0.01^{b}$ & $0 \cdot 12^{b}$ & $0.30^{\mathrm{a}}$ & 0.042 & 0.083 & 0.932 & 0.001 \\
\hline Erucic acid (22:1n-9) & $0.07^{b}$ & $0.07^{b}$ & $0 \cdot 13^{b}$ & $0.41^{a}$ & 0.035 & 0.456 & 0.145 & 0.035 \\
\hline Docosatetraenoic acid $(22: 4 n-6)$ & 0.00 & 0.00 & 0.01 & 0.01 & 0.002 & 0.035 & 0.541 & 0.468 \\
\hline Docosapentaenoic acid (22:5n-3) & $0.01^{\mathrm{b}}$ & $0.02^{b}$ & $0 \cdot 12^{b}$ & $0.28^{a}$ & 0.064 & 0.024 & 0.682 & 0.029 \\
\hline DHA $(22: 6 n-3)$ & 0.01 & 0.01 & 0.02 & 0.02 & 0.003 & 0.365 & 0.245 & 0.258 \\
\hline Lignoceric acid (24:0) & 0.01 & 0.01 & $0 \cdot 13$ & 0.15 & 0.023 & 0.003 & 0.964 & 0.358 \\
\hline Nervonic acid $(24: 1 n-9)$ & $0.33^{\mathrm{a}, \mathrm{b}}$ & $0.11^{c}$ & $0.25^{b}$ & $0.39^{a}$ & 0.043 & 0.045 & 0.011 & 0.042 \\
\hline
\end{tabular}

a,b,c Mean values within a row with unlike superscript letters were significantly different $(P<0.05)$

* Mean values with their pooled standard errors ( $n 6$ per treatment).

$\dagger$ Contrast statements: fibre $=$ cellulose $v$. pectin; lipid $=$ maize oil $v$. beef tallow; $F \times L=$ interaction of dietary fibre and lipid type. 
Table 6. Faecal fatty acid flow in pigs fed the experimental diets ( $\mathrm{mg} / \mathrm{kg} \mathrm{DM}$ intake)* (Mean values with their standard errors)

\begin{tabular}{|c|c|c|c|c|c|c|c|c|}
\hline \multirow[b]{2}{*}{ Item } & \multicolumn{2}{|c|}{ Cellulose } & \multicolumn{2}{|c|}{ Pectin } & \multirow[b]{2}{*}{ SEM } & \multicolumn{3}{|c|}{$P \dagger$} \\
\hline & Maize oil & Beef tallow & Maize oil & Beef tallow & & Fibre & Lipid & $\mathrm{F} \times \mathrm{L}$ \\
\hline Caprylic acid (8:0) & $0.46^{\mathrm{b}}$ & $0.42^{b}$ & $0.61^{\mathrm{a}}$ & $0.26^{\mathrm{C}}$ & 0.129 & 0.001 & 0.595 & 0.041 \\
\hline Capric acid $(10: 0)$ & 0.23 & 0.19 & 0.35 & 0.33 & 0.031 & $<0.001$ & 0.429 & 0.635 \\
\hline Lauric acid (12:0) & $3 \cdot 17^{\mathrm{a}}$ & $1.61^{\mathrm{b}}$ & $3.05^{\mathrm{a}}$ & $1.69^{\mathrm{b}}$ & 0.475 & 0.325 & 0.976 & $<0.001$ \\
\hline Myristic acid $(14: 0)$ & $26 \cdot 96$ & $14 \cdot 17$ & $20 \cdot 12$ & 21.90 & 5.623 & 0.456 & 0.878 & 0.563 \\
\hline Myristoleic acid (14:1) & $8 \cdot 88^{a, b}$ & $3 \cdot 19^{b}$ & $11.45^{\mathrm{a}}$ & $4.57^{b}$ & $3 \cdot 125$ & 0.069 & 0.036 & $<0.001$ \\
\hline Pentadecyclic acid (15:0) & $42 \cdot 33$ & 20.03 & $32 \cdot 26$ & 28.06 & $7 \cdot 634$ & $<0.001$ & 0.014 & 0.751 \\
\hline Palmitic acid $(16: 0)$ & 537.1 & $410 \cdot 9$ & 443.6 & 464.4 & $72 \cdot 36$ & $<0.001$ & 0.799 & $0 \cdot 101$ \\
\hline Palmitelaidic acid $(16: 1 t)$ & $0.22^{c}$ & $0.25^{\mathrm{c}}$ & $0.79^{a}$ & $0.55^{\mathrm{b}}$ & 0.136 & 0.446 & 0.633 & $<0.001$ \\
\hline Palmitoleic acid $(16: 1 n-7)$ & 1.38 & 1.08 & $2 \cdot 68$ & $2 \cdot 85$ & 0.357 & 0.369 & 0.489 & 0.352 \\
\hline Margaric acid $(17: 0)$ & 38.95 & $21 \cdot 10$ & $25 \cdot 69$ & $26 \cdot 29$ & $14 \cdot 332$ & 0.098 & 0.695 & 0.631 \\
\hline Stearic acid $(18: 0)$ & 671.6 & 740.9 & 588.8 & 654.9 & $75 \cdot 04$ & $<0.001$ & 0.878 & 0.151 \\
\hline Oleic acid $(18: 1 n-9)$ & $92 \cdot 5$ & $90 \cdot 0$ & 172.5 & $82 \cdot 3$ & $115 \cdot 12$ & 0.745 & 0.581 & 0.761 \\
\hline Vaccenic acid $(18: 1 n-7)$ & $10 \cdot 03$ & 8.09 & $9 \cdot 38$ & $14 \cdot 27$ & $4 \cdot 122$ & 0.332 & 0.564 & 0.156 \\
\hline Linoleic acid $(18: 2)$ & $14 \cdot 4^{\mathrm{b}}$ & $18 \cdot 6^{\mathrm{b}}$ & $99 \cdot 5^{\mathrm{a}}$ & $13 \cdot 8^{\mathrm{b}}$ & $16 \cdot 72$ & 0.864 & 0.932 & $<0.001$ \\
\hline Linolenic acid $(18: 3 n-6)$ & 1.79 & 0.68 & 0.87 & 1.36 & $2 \cdot 171$ & 0.385 & 0.111 & 0.458 \\
\hline$a$-Linolenic acid $(18: 3 n-3)$ & 3.05 & $2 \cdot 18$ & 1.09 & 3.87 & $4 \cdot 243$ & 0.824 & 0.333 & 0.564 \\
\hline Arachidic acid $(20: 0)$ & $25 \cdot 06^{\mathrm{b}}$ & $28 \cdot 23^{\mathrm{b}}$ & $36 \cdot 08^{a}$ & $27 \cdot 73^{b}$ & 2.735 & 0.687 & 0.964 & 0.032 \\
\hline Gadoleic acid (20:1) & $7 \cdot 76$ & $5 \cdot 62$ & 11.00 & 7.44 & 3.223 & 0.045 & 0.406 & 0.153 \\
\hline Eicosadienoic acid (20:2) & 0.33 & 0.24 & 0.96 & 0.59 & 0.354 & 0.354 & 0.878 & 0.381 \\
\hline Dihomo- $\gamma$-linolenic acid $(20: 3 n-6)$ & $0.00^{\mathrm{C}}$ & $0.02^{\mathrm{b}, \mathrm{c}}$ & $0 \cdot 12^{\mathrm{a}}$ & $0.06^{\mathrm{b}}$ & 0.021 & 0.375 & 0.406 & 0.024 \\
\hline Eicosatrienoic acid $(20: 3 n-3)$ & 0.55 & 0.71 & 0.92 & 0.84 & 0.258 & $<0.001$ & 0.041 & 0.101 \\
\hline Arachidonic acid $(20: 4 n-6)$ & 0.12 & $0 \cdot 16$ & 0.79 & 0.49 & 0.522 & $<0.001$ & 0.581 & 0.521 \\
\hline EPA $(20: 5 n-3)$ & $0.08^{b}$ & $0.04^{b}$ & $0 \cdot 33^{a}$ & $0.00^{\mathrm{b}}$ & 0.022 & $<0.001$ & 0.034 & 0.043 \\
\hline Behenic acid $(22: 0)$ & 8.41 & $10 \cdot 28$ & $16 \cdot 58$ & 11.92 & $6 \cdot 679$ & $<0.001$ & 0.014 & 0.201 \\
\hline Erucic acid $(22: 1 n-9)$ & $0.67^{a}$ & $0.07^{b}$ & $0.53^{\mathrm{a}}$ & $0.73^{\mathrm{a}}$ & 0.272 & 0.348 & 0.932 & $<0.001$ \\
\hline Docosatetraenoic acid $(22: 4 n-3)$ & 0.00 & 0.07 & 0.28 & 0.00 & 0.423 & 0.824 & 0.333 & 0.564 \\
\hline Docosapentaenoic acid $(22: 5 n-3)$ & $43 \cdot 72^{\mathrm{a}}$ & $22.55^{\mathrm{b}}$ & $37.89^{a}$ & $23.45^{\mathrm{b}}$ & $6 \cdot 112$ & 0.024 & 0.682 & 0.011 \\
\hline Lignoceric acid (24:0) & $8 \cdot 70^{\mathrm{b}}$ & $0.07^{c}$ & $24 \cdot 37^{\mathrm{a}}$ & $10 \cdot 49^{b}$ & 2.733 & 0.003 & 0.079 & 0.024 \\
\hline Nervonic acid (24:1n-9) & 3.84 & $2 \cdot 56$ & $4 \cdot 36$ & 4.39 & $2 \cdot 734$ & 0.633 & 0.484 & 0.578 \\
\hline
\end{tabular}

a,b,c Mean values within a row with unlike superscript letters were significantly different $(P<0.05)$

* Mean values with their pooled standard errors ( $n 6$ per treatment).

$\dagger$ Contrast statements: fibre $=$ cellulose $v$. pectin; lipid $=$ maize oil $v$. beef tallow; $F \times L=$ interaction of dietary fibre and lipid type.

$20: 3 n-6,20: 5 n-3,22: 1 n-9,22: 5 n-3$ and $24: 0$. The addition of beef tallow decreased $(P<0.05)$ the flow of faecal $8: 0,14: 1$, $16: 1 t, 18: 2,20: 0,20: 3 n-6$ and $20: 5 n-3$ in the diet containing pectin but did not induce effects in the cellulose-containing diet. Dietary supplementation with beef tallow decreased faecal flows of $12: 0,22: 5 n-3$ and $24: 0$ in cellulose- and pectin-containing diets. The addition of beef tallow decreased $(P>0.05)$ the caecal flow of $22: 1 n-9$ in the diet containing cellulose but did not have effects in the pectin-containing diet. There were no $(P>0.05)$ interactive effects between DF and lipid types on the faecal flow of $10: 0,14: 0,15: 0,16: 0,16: 1 n-7,17: 0,18: 0,18: 1 n-9$, $18: 1 n-7,18: 2,18: 3 n-6,18: 3 n-3,20: 1,20: 2,20: 3 n-3,20: 4 n-6$, $22: 0,22: 4 n-3$ and $24: 1 n-9(P>0 \cdot 05)$. The main effects of DF type increased $(P>0 \cdot 05)$ the faecal flow of $10: 0,20: 3 n-3,20: 4 n$ 6 and $22: 0$ in diets containing pectin compared with cellulosecontaining diets. The main effects of lipid type decreased $(P>0.05)$ the flow of faecal 15:0 in the diet containing beef tallow compared with the diet containing maize oil. The main effects of DF type decreased $(P>0.05)$ the flow of faecal 18:0 in diets containing pectin compared with the cellulose-containing diets.

\section{Discussion}

The soluble, insoluble and total DF contents of the diets were not determined in this study, however, as expected, the diets containing pectin and those containing cellulose differed substantially in the content of NSP. Cellulose is an insoluble fibre made up of straight chains of glucose units that are generally linked by $\beta$ - $(1 \rightarrow 4)$ bonds ${ }^{(1,2,6)}$. Conversely, pectin is a branched polymer of galacturonic acids that are linked by $\alpha$ - $(1 \rightarrow 4)$ glycosidic linkages and is classified as a soluble fibre ${ }^{(1,2,6)}$. Therefore, due to the differences in their well-known solubility properties and monomeric compositions, cellulose and pectin polysacharides were incorporated in diets used in this trial to create different conditions in different segments of the GIT. Moreover, the slightly higher fat content in beef tallow diets than in maize oil diets is attributable to high inclusion in diet formulation to achieve isoenergetic values across all diets as it is well known that beef tallow has a lower energy value than maize oil. The TFA contents were similar among all diets but the SFA, unsaturated FA, MUFA and PUFA profiles were different between beef tallow- and maize oil-containing diets.

The observation that addition of maize oil in pectin diets depressed digestibility of DM in the ileum was unexpected and contradicts our observation that dietary supplementation with beef tallow depressed digestibility of DM in cellulose-containing diets in the entire GIT. These discrepancies could be attributed to the variation in the endogenous enzymatic activity and differences in microbiota compositions and activity induced by the uniqueness in the behaviour of the DF and its influence on physicochemical properties of digesta in pigs fed different fibre 
sources ${ }^{(6,7,32)}$. Furthermore, the presence of charged regions within the branched galacturonic acid residues in pectin could have created more surface area for the non-convalent interactions with the absorbant to be formed for FA in beef tallow compared to cellulose straight chains that are less charged and closely packed together by the hydrogen bonds between the strands $^{(6)}$. Therefore, our observations further suggest that absorption of nutrients differs depending on the physicochemical property of the fibre source, the segment of the gut as well as the level of saturation of FA in added dietary lipids ${ }^{(6,7,13,16)}$. The observation that AID of DM was greater and ACD of DM tended to be greater in pectin diets compared with cellulose diets concurs with the findings of Drochner et al. ${ }^{(33)}$. Drochner et al. ${ }^{(33)}$ predicted that the extent of depression of organic matter digestibility when $5 \%$ pectin is included in a diet will not be as high as with cellulose. Our data show that ileal and caecal digestibility of DM in pectin diets were greater compared with cellulose diets, which could be ascribed to the uniqueness of the constituent monomers between the two polysaccharides. Unlike cellulose which is made up of sugars joined together in straight chains to give it a hydrophobic and crystalline structure that is only modestly accessible to microbial degradation, pectins are branched polymers of galacturonic acids that are soluble and accessible to microbial fermentation $^{(34,35)}$. Therefore, the branched chains in pectin offers a greater surface area for the interaction between the fibre and the FA in beef tallow compared cellulose polymers, resulting in inconsistencies in digestibility of not only DM but also dietary lipids depending on the degree of saturation of the constituent $\mathrm{FA}^{(36)}$. Supporting this phenomenon is the notion that depending on their degree of saturation of the FA, lipids may depress microbial fibrolytic activity by forming a film of adsorbate on the surface of the fibre matrix, resulting in slow caption of amino acids and production of ATP needed to support bacterial fermentation ${ }^{(37)}$.

DF can inhibit the catalytic activity of digestive enzymes (including lipases) by interacting directly with the enzymes at molecular level through electrostatic, hydrogen bonding or hydrophobic interactions that alter the enzyme conformation $^{(6)}$. There was evidence for the interaction effect of DF and lipid types on AID of SFA, MUFA, PUFA and TFA, ACD of SFA, MUFA and TFA and ATTD of PUFA. The apparent digestibility of TFA at the end of the ileum and over the entire GIT was lower for pectin-containing diets than for diets containing cellulose. Although we did not quantify the fibre components in each diet, this is likely a result of greater concentration of soluble fibre fractions in digesta of pigs fed diets containing pectin compared to those fed diets containing cellulose. Drochner et $a l{ }^{(33)}$ also observed that pectin depressed fat digestibility by binding BA and reducing their capacity to emulsify fats. Alternatively, pectin can inhibit pancreatic lipase by forming a complex with the enzyme thereby disrupting binding between the lipid droplets and enzyme active site or altering protonation of lipase active site by carboxylic acids residues of pectin ${ }^{(6,38,39)}$. Moreover, the addition of beef tallow further depressed digestibility of TFA in pectin diets compared with cellulose diets, and this could be ascribed to high contents of 16:0 and 18:0 that contribute approximately
$35 \%$ SFA in beef tallow. The AID of SFA decreases with increasing chain lengths ${ }^{(40,41)}$. Supplementation with beef tallow increased the ileal digestibility of SFA, but the increment was pronounced more in pectin diets compared with cellulose diets. Because a greater proportion of pectin disappears in the small intestines, implying that there is less interaction between DF fractions from pectin and SFA, yet in cellulose diets more IDF fractions from cellulose reach the distal regions of the intestines.

Previous reports by Pomerenke $e^{(42)}$ and Davis et al. ${ }^{(43)}$ reported that addition of $30 \%$ IDF from dried distiller's grains with solubles (DDGS) reduced digestibility of 16:0 and total SFA in comparison with addition of 0 or $5 \%$ fibre from DDGS, which was likely due to an interaction between DF and lipid sources. Kim et al. ${ }^{(44)}$ also proposed that fibre matrix surround the TAG and consequently impede the digestion process by preventing lipase from assessing the lipid. Therefore, these observations strongly support the notion that absorption of SFA are reduced when tallow is added to a diet that is rich in insoluble fibre compared with the one supplemented with soluble fibre. The same phenomenon was also noticed with AID of PUFA whereby the addition of beef tallow in pectin diets increased PUFA digestibility but supplementation with cellulose depressed digestibility. Furthermore, our findings are also in agreement with previous reports suggesting that digestibility of SFA, and 16:0 in particular, is greater in beef tallow-containing diets compared with other vegetable-based lipid sources such as rapeseed, sunflower and flaxseed oils ${ }^{(45-47)}$. Another plausible explanation for the decrease in the digestibility of SFA in diets supplemented with maize oil could be due to an increase in the ileal flow of 18:0 as a result of its formation from biohydrogenation processes of PUFA and specifically $18: 2$ which increased in the $\mathrm{GIT}^{(48)}$. In the present study, the dietary level of PUFA was high in maize oil-supplemented diets, however, biohydrogenation rates of PUFA are more pronounced in the hindgut than in the distal ileum ${ }^{(46,49)}$. In the present study, it is well established that MUFA represents over $50 \%$ of the total lipids in pork fat deposits ${ }^{(50)}$ and represents almost a third of TFA in maize oil diets and approximately one-half of the TFA in beef tallow-containing diets. The observation that SFA were numerically less digestible compared with MUFA and PUFA can be ascribed to the postulation that due to their lipid structure, SFA has a lower ability than MUFA or PUFA to form micelles and cross the water layer ${ }^{(51-53)}$

Apart from other dietary factors, the digestibility of lipids in the hindgut is influenced by several factors including endogenous secretion from mucosal cells, sloughing of epithelial cells or de novo synthesis by gastrointestinal microbiota ${ }^{(54)}$. It is interesting to note that regardless of the lipid or fibre source, the ACD of lipids was lower than the AID of lipids in all diets. The lower digestibility of ACD of lipids can be attributed to the effects of DF that initiated inefficient digestibility and suboptimal absorption of dietary fat due to deconjugation of BA by increased bacterial activity in the intestinal lumen ${ }^{(17)}$. These processes reduce the solubility and emulsifying capacity of BA, and consequently they are bound to bacterial cells and DF, thereby increasing their excretion as reported in our previous study ${ }^{(17,55)}$. Supporting these notions is the observed intestinal 
flow of FA that were virtually absent in the diets but increased in different sections of the GIT. For example, the flow of $8: 0$, $17: 0,18: 3 n-6,20: 3 n-3,18: 1 n-7,20: 4 n-6$ and $24: 1, n-9$ increased in the terminal ileum. The increases in $n-3$ and $n-6$ FA flow indicate a likelihood of activity of the $\Delta 6$ - and $\Delta 5$-desaturases and chain-elongases in the upper sections of the GIT of the pig ${ }^{(48)}$. More work is needed to explain the role played by gastrointestinal microbiota in elongating or desaturating FA such as $18: 2 n-6$ and $18: 3 n-3$ and the extent by which microbial fermentation contributes to an increase in the presence of unsaturated FA in the digesta of pigs. There was an increase in the caecal flow of $18: 3 n-6,20: 3 n-3,20: 4 n-6$ and $22: 5 n-6$ more in pigs that were fed pectin-containing diets than in those fed cellulose-containing diets, suggesting that microbiota played a central role in the production of these long-chain FA. Thus, the increase in flow of these FA could also be attributed to the action of microbiota such as Butyrivibrio fibrisolvens through biosynthesis or other unknown bacteria that can facilitate the biodehydrogenation processes ${ }^{(48)}$. Furthermore, the finding that the flows of $18: 1$ decreased along the GIT occurred at the same time when 18:2 increased supports a fact that is well established in ruminants that feeding high-fibre diets stimulated the synthesis of the former through $\Delta 9$ desaturation from 18:1 precursor ${ }^{(56)}$. However, the increase in digestibility of lipids in diets containing cellulose and maize oil can be ascribed to the decrease in the flow of FA in the colon. Moreover, the lower ATTD of lipids in pectin-containing diets can be partly attributed to the content of mucilage in pectin or microbial production of FA following the conversion of SCFA into elongated forms of FA or the contribution of endogenous losses of FA from the host to the intestinal flow of FA. Nevertheless, even though long-chain FA cannot be absorbed in the hindgut, their production is obviously irrelevant to the NEFA pool in the porcine blood but could indirectly affect lipid metabolism by influencing microbial activities that play a central role in SCFA production.

In general, the AID of DM was lower than the ATTD values, whereas the values for ACF of DM were intermediate. The ileal and total tract digestibility values of DM in cellulose diets in the current study were lower than that reported by Hooda et al. ${ }^{(57)}$ with regard to ileal cannulated pigs fed $52.0 \mathrm{~g} / \mathrm{kg}$ of cellulose in the diet. The inconsistencies in the digestibility values in this study and the previous report ${ }^{(57)}$ can be attributed to the differences in the source and dietary inclusion levels of cellulose used in the two experiments. Although the marginal differences between AID and ACD of DM were more pronounced in the cellulose diets compared with pectin diets, they are in agreement with the previous notions postulated by Jaworski \& Stein ${ }^{(14)}$ that a significant part of the DF fermentation occurs in the caecum. Furthermore, these marginal differences suggest that since microbial degradation of pectin fibres commences in the upper gastrointestinal segments ${ }^{(58,59)}$, the fermentability of soluble fibre fractions of such pectin occurs at a lower extend in the caecum or colon compared to insoluble fibre components including cellulose. More work is required to determine the interactive effects of DF and lipid types on fermentability of DF fractions in different gut segments in growing pigs fed different sources of natural fibres and supplementary lipids. Although we cannulated in the caecum $5 \mathrm{~cm}$ proximal to the caecocolic junction, Jaworski \& Stein ${ }^{(14)}$ predicted fermentability of DF in the caecum using cannulas that were inserted in the colon $20 \mathrm{~cm}$ distal to the caecum. In accordance with our findings, these authors also indicated that the fermentability of DF fractions varies along the GIT. Cannulation inside the caecum could have imposed some limitations to the caecal digestibility values especially with regard to the potential backflow that may arise due to the uncontrolled peristaltic movements of the gastrointestinal muscles. Taken together, our data suggest that the source of lipids supplemented in high-fibre diets also influence the extent of DM digestibility, also depending on the source of the DF.

Although this study had some limitations, its results also have implications that could be of interests not only in swine nutrition but also in human nutrition. In this regard, the study opens the ways to understanding the role played by interactive effects of DF sources and the degree of FA saturation in dietary lipids, and their ability to create different conditions in the gastrointestinal milieu. One limitation was that to achieve isoenergetic and iso-nutritious diets in feed formulation, $150 \mathrm{~g} / \mathrm{kg}$ of either pectin or cellulose was included in each diet, resulting in a confounded higher content of NSP (13\%) in the cellulosecontaining diets compared to the lower content of NSP (9.9\%) in pectin-containing diets. This implies that pigs fed diets with cellulose consumed significantly more DF compared with pigs fed diets with pectin. Another limitation was that there is a general increase in the flow of FA from one segment to the other, but it is still difficult to identify the actual source of lipids excreted in the terminal ileum, caecum or faeces. This implies that the use of isotope-labelled FA would open way for future studies to pinpoint whether FA in different gastrointestinal segments originate from the diet, endogenous secretions or microbial activities following deconjugation of BA and/or microbial bioconversion of dietary FA or endogenous lipids into microbial FA. Considering that human healthcare practitioners strongly recommend that patients increase DF in their rations and beef tallow tended to depress ATTD of DM in cellulose diets and increase AID of DM in pectin diets in this study, it is of paramount importance that if the intended value of the fibre source is to be achieved, one must decide when to take butter or fatty meat products $v$. vegetable oil-enriched foods. Among vegetable oils, palm oil could be an exception because of its high unsaturated FA content. More work is needed to investigate the interactions between DF solubility and lipid saturation using natural sources of fibre and at levels of inclusion for a practical dietary intervention that would be feasible for implementation in real-life human and swine feeding situations.

In conclusion, dietary inclusion of cellulose and pectin differently modulates the conditions in different segments of the GIT, thereby altering the apparent digestibility and flows of gastrointestinal FA. The interaction between DF and lipid types modulates digestibility of lipids and FA flows but differs for saturated and unsaturated FA and varies in different gastrointestinal segments. The digestibility of lipids is depressed and FA flows are increased in pectin-containing diets but more in diets supplemented with beef tallow than in all 
cellulose-containing diets. More work is needed to investigate how different fibre sources modulate conditions in different segments of the GIT and promote the endogenous losses of FA or microbial production or biotransformation of dietary and/or endogenous lipids.

\section{Acknowledgements}

The authors wish to thank DuPont Industrial Biosciences (Danisco UK Ltd) for financially supporting this research project. The authors are also grateful to the technical staff at the Department of Animal Biosciences at University of Guelph for postsurgical animal care (Douglas C. Wey) and in particular Wilfredo D. Mansilla and Cuilan L. Zhu for conducting surgeries.

The authors' contributions are as follows: S. P. N., E. K., C. F. M. d. L. and C. M. N. designed the study. S. P. N. conducted the animal study, the statistical analysis and wrote the manuscript as part of his graduate studies. E. K., M. C. W., N. A., and C. M. N. critically reviewed the manuscript. C. M. N. was the principal investigator who supervised all aspects of the study. All the authors read, edited and approved the final manuscript.

The authors declared that there are no conflicts of interest.

\section{References}

1. Bach Knudsen KE (2001) The nutritional significance of "dietary fibre" analysis. Anim Feed Sci Technol 90, 3-20.

2. Agyekum AK \& Nyachoti CM (2017) Nutritional and metabolic consequences of feeding high-fiber diets to swine: a review. Engineering 3, 716-725.

3. Bergman EN (1990) Energy contributions of volatile fatty acids from the gastrointestinal tract in various species. Physiol Rev 70, 567-590.

4. Montoya CA, Rutherfurd SM \& Moughan PJ (2016) Kiwifruit fibre level influences the predicted production and absorption of SCFA in the hindgut of growing pigs using a combined in vivo-in vitro digestion methodology. Br J Nutr 115, $1317-1324$

5. Ravindran $\mathrm{V}$, Tancharoenrat $\mathrm{P}$, Zaefarian $\mathrm{F}$, et al. (2016) Fats in poultry nutrition: digestive physiology and factors influencing their utilisation. Anim Feed Sci Technol 213, 1-21.

6. Capuano E (2017) The behavior of dietary fiber in the gastrointestinal tract determines its physiological effect. Crit Rev Food Sci Nutr 57, 3543-3664.

7. Ndou S, Gous R \& Chimonyo M (2013) Prediction of scaled feed intake in weaner pigs using physico-chemical properties of fibrous feeds. B J Nutr 110, 774-780.

8. Bakker GCM (1996) Interaction between carbohydrates and fat in pigs-impact on energy evaluation of feeds. PhD Thesis, Wageningen Agricultural University.

9. O'Doherty JV, McGlynn SG \& Murphy D (2002) The influence of fibre level and fat supplementation in expander-processed diets on grower-finisher pig performance. J Sci Food Agric $\mathbf{8 2}$, 1036-1043.

10. Ball MEE, Magowan E, Beattie VE, et al. (2010) The effect of dietary energy source on performance and nutrient digestibility in growing pigs. J Anim Feed Sci 19, 408-417.

11. Gutierrez NA, Kerr BJ \& Patience JF (2013) Effect of insolublelow fermentable fiber from corn-ethanol distillation origin on energy, fiber, and amino acid digestibility, hindgut degradability of fiber, and growth performance of pigs. J Anim Sci 91, 5314-5325.
12. Brooks CC, Garner GB, Gehrke CW, et al. (1954) The effect of added fat on the digestion of cellulose and protein by ovine rumen micro-organisms. J Anim Sci 13, 758-764.

13. Mallett AK \& Rowland IR (1988) Factors affecting the gut microflora. In Role of the Gut Flora in Toxicity and Cancer, pp. 347-382 [IR Rowland, editor]. London: Academic Press.

14. Jaworski NW \& Stein HH (2017) Disappearance of nutrients and energy in the stomach and small intestine, cecum, and colon of pigs fed corn-soybean meal diets containing distillers dried grains with solubles, wheat middlings, or soybean hulls. J Anim Sci 95, 727-739.

15. Graham H, Hesselman K \& Åman P (1986) The influence of wheat bran and sugar-beet pulp on the digestibility of dietary components in a cereal-based pig diet. J Nutr 116, 242-251.

16. Bach Knudsen KE \& Hansen I (1991) Gastrointestinal implications in pigs of wheat and oat fractions. 1. Digestibility and bulking properties of polysaccharides and other major constituents. Br J Nutr 65, 217-232.

17. Ndou SP, Kiarie E, Thandapilly SJ, et al. (2017) Flaxseed meal and oat hulls supplementation modulates growth performance, blood lipids, intestinal fermentation, bile acids, and neutral sterols in growing pigs fed corn-soybean mealbased diets. J Anim Sci 95, 3068-3078.

18. Judd PA \& Truswell AS (1981) The effect of rolled oats on blood lipids and fecal steroid excretion in man. Am J Clin Nutr 34, 2061-2067.

19. Ahn TY, Kim GB, Lim KS, et al. (2003) Deconjugation of bile salts by Lactobacillus acidobacillus isolates. Int J Dairy $\mathbf{1 3}$, 303-311.

20. Kil DY, Sauber TE, Jones DB, et al. (2010) Effect of the form of dietary fat and the concentration of dietary neutral detergent fiber on ileal and total tract endogenous losses and apparent and true digestibility of fat by growing pigs. J Anim Sci $\mathbf{8 8}$, 2959-2967.

21. Canadian Council on Animal Care (2009) Guide to the Care and Use of Experimental Animals. Ottawa: Canadian Council on Animal Care.

22. Nyachoti CM, McNeilage-Van de Wiele EM, De Lange CFM, et al. (2002) Evaluation of the homoarginine technique for measuring true ileal amino acid digestibilities in pigs fed a barley-canola meal-based diet. J Anim Sci 80, 440-448.

23. National Research Council (2012) Nutrient Requirements of Swine, 11th ed. Washington, DC: National Academies Press.

24. Association of Official Analytical Chemists (1990) Official Methods of Analysis of AOAC International, 16th ed. Washington, DC: AOAC.

25. Lomer MCE, Thompson RPH, Commisso J, et al. (2000) Determination of titanium dioxide in foods using inductively coupled plasma optical emission spectrometry. Analyst 125, 2339-2343

26. Folch J, Less M \& Sloane-Stanley GH (1957) A simple method for the isolation and purification of total lipids from animal tissue. Biol Chem 226, 497-509.

27. Metcalfe LD \& Schmitz AA (1961) The rapid preparation of fatty acid esters for gas chromatographic analysis. Anal Chem 33, 363-364

28. American Oil Chemists' Society (1998) Official Methods and Recommended Practices of the AOCS, 5th ed. Champaign, IL: AOCS.

29. Madsen A, Jakobsen K \& Mortensen HP (1992) Influence of dietary fat on carcass fat quality in pigs: a review. Acta Agric Scand 42, 220-225.

30. SAS Institute Inc. (2013) Base $S A S^{\circledR} 9.4$ Procedures Guide: Statistical Procedures, 2nd ed. Cary, NC: SAS Institute Inc.

31. Bowley S (editor) (2015) A Hitchbiker's Guide to Statistics in Biology, Generalized Linear Mixed Model Edition. Kincardine, ON: Plants et al. Inc. 
32. Ndou SP, Tun HM, Kiarie E, et al. (2018) Dietary supplementation with flaxseed meal and oat hulls modulates intestinal histomorphometric characteristics, digesta- and mucosa-associated microbiota in pigs. Sci Rep $\mathbf{8}, 5880$.

33. Drochner W, Kerler A \& Zacharias B (2004) Pectin in pig nutrition, a comparative review. J Anim Physiol A Anim Nutr 88, 367-380.

34. Bach Knudsen KE \& Hansen I (1991) Gastrointestinal implications in pigs of wheat and oat fractions. 1. Digestibility and bulking properties of polysaccharides and other major constituents. Br J Nutr 65, 217-232.

35. Wilfart A, Montagne L, Simmins H, et al. (2007) Sites of nutrient digestion in growing pigs: effects of dietary fiber. J Anim Sci 85, 976-983.

36. Mateos GG, Sell JL \& Eastwood JA (1982) Rate of food passage (transit time) as influenced by level of supplemental fat. Poult Sci 61, 94-100.

37. Galbraith H \& Miller TB (1973) Effect of long chain fatty acids on bacterial respiration and amino acid uptake. $J$ Appl Bacteriol 36, 659-675.

38. Isaksson G, Lundquist I \& Ihse I (1982) In vitro inhibition of pancreatic enzyme activities by dietary fiber. Digestion 24, 54-59.

39. Kumar A \& Chauhan GS (2010) Extraction and characterization of pectin from apple pomace and its evaluation as lipase (steapsin) inhibitor. Carbohydr Polym 82, 454-459.

40. Cera KR, Mahan DC \& Reinhart GA (1988) Weekly digestibilities of diets supplemented with corn oil, lard or tallow by weanling swine. J Anim Sci 66, 1430-1437.

41. Cera KR, Mahan DC \& Reinhart GA (1989) Apparent fat digestibilities and performance responses of postweaning swine fed diets supplemented with coconut oil, corn oil or tallow. J Anim Sci 67, 2040-2047.

42. Pomerenke J (2012) Assesment of the effects of diets containing DDGS with supplemental tallow on fat digestibility, growth performance, carcass and pork fat quality in growingfinishing pigs. MS Thesis, University of Minnesota.

43. Davis JM, Urriola PE, Shurson GC, et al. (2015) Effects of adding supplemental tallow to diets containing $30 \%$ distillers dried grains with solubles on growth performance, carcass characteristics, and pork fat quality in growing-finishing pigs. J Anim Sci 93, 266-277.

44. Kim BG, Kil DY \& Stein HH (2013) In growing pigs, the true ileal and total tract digestibility of acid hydrolyzed ether extract in extracted corn oil is greater than in intact sources of corn oil or soybean oil. J Anim Sci 91, 755-763.

45. Ozimek L, Sauer WC, Kozikowski W, et al. (1984) The ileal and fecal digestibility of fat and fatty acids in pigs fed semipurified diets containing beef tallow or rapeseed oil. In 63rd Annual Feeders' Day Report, pp. 14-16. Canada: University of Alberta, Agriculture and Forestry Bulletin.
46. Duran-Montgé P, Lizardo R, Torrallardona D, et al. (2007) Fat and fatty acid digestibility of different fat sources in growing pigs. Livest Sci 109, 66-69.

47. Mitchaothai J, Everts H, Yuangklang C, et al. (2007) Meat quality, digestibility and deposition of fatty acids in growingfinishing pigs fed restricted, isoenergetic amounts of diets containing either beef tallow or sunflower oil. J Anim Sci 21, $1015-1026$

48. Martínez-Ramírez HR, Kramer JKG \& de Lange CFM (2013) Ileal flows and apparent ileal digestibility of fatty acids in growing gilts fed flaxseed containing diets. J Anim Sci 91, 2729-2739.

49. Jørgensen H, Gabert VM, Hedemann MS, et al. (2000) Digestion of fat does not differ in growing pigs fed diets containing fish oil, rapeseed oil or coconut oil. J Nutr 130, 852-857.

50. Xu G, Baidoo SK, Johnston LJ, et al. (2010) Effects of feeding diets containing increasing content of corn distillers dried grains with solubles to grower-finisher pigs on growth performance, carcass composition, and pork fat quality. J Anim Sci 88, 1398-1410.

51. Jørgensen H, Jakobsen K \& Eggum BO (1993) Determination of endogenous fat and fatty acids at the terminal ileum and in faeces in growing pigs. Acta Agric Scand Sect A 43, 101-106.

52. Overland M, Mroz Z \& Sundstol F (1994) Effect of lecithin on the apparent ileal and overall digestibility of crude fat and fatty acids in pigs. J Anim Sci 72, 2022-2028.

53. Powles J, Wiseman J, Cole DJA, et al. (1994) Effect of chemical structure of fats upon their apparent digestible energy value when given to young pigs. Anim Sci 58, 411-417.

54. González-Muñoz MJ, Bastida S \& Sanchez-Muniz FJ (2003) Short-term in vivo digestibility assessment of a highly oxidized and polymerized sunflower oil. J Sci Food Agric 83, 413-418.

55. Ndou SP, Kiarie E, Ames N, et al. (2018) Flaxseed meal and oat hulls supplementation: Impact on dietary fiber digestibility, and flows of fatty acids and bile acids in growing pigs. $J$ Amin Sci (epublication ahead of print version 15 October 2018).

56. Bauman DE \& Griinari JM (2003) Nutritional regulation of milk fat synthesis. Annu Rev Nutr 23, 203-227.

57. Hooda S, Metzler-Zebeli B, Vasanthan T, et al. (2011) Effects of viscosity and fermentability of dietary fibre on nutrient digestibility and digesta characteristics in ileal-cannulated grower pigs. Br J Nutr 106, 664-674.

58. Bach Knudsen KE, Lærke HN \& Jørgensen H (2013) Carbohydrates and carbohydrate utilization in swine. In Sustainable Swine Nutrition, pp. 109-135 [LI Chiba, editor]. Ames, IA: John Wiley \& Sons.

59. Montoya CA, Rutherfurd SM \& Moughan PJ (2017) Ileal digesta nondietary substrates from cannulated pigs are major contributors to in vitro human hindgut short-chain fatty acid production. J Nutr 147, 264-271. 